\title{
THE INVISIBLE INFLUENCE
}

\section{Amid global calls to end drug companies' direct sponsorship of doctors' education, an investigation in Australia reveals sponsor involvement in the education of thousands of GPs, writes Ray Moynihan}

\section{W} e've all been there-the educational seminars, the medical symposiums, and the scientific conferences generously sponsored by big drug companies. The visible signs of sponsorship at these events are obvious: the smiling drug company representatives, the colourful company logos, and the high tech stalls in the exhibit halls. But what about inside lecture theatres, where high quality education is delivered to doctors by respected speakers? Surely the sponsors have no input into those sacred places of independent education?

It seems that invisible influence may be flowing through these sponsored seminars-even those accredited by august associations-far more often than many of us realise. In a rare look behind the scenes of sponsored medical education, the Australian Broadcasting Corporation's Background Briefing programme (www.abc.net. $\mathrm{au} / \mathrm{rn} /$ backgroundbriefing/) will this weekend show that it is not uncommon for drug company sponsors to suggest speakers at sessions that are assumed by the thousands of general practitioners who attend them to be totally independent. Drug industry representatives have confirmed that similar practices take place in the United Kingdom, where roughly half of all education for doctors is sponsored by drug companies.

In the case of one popular Australian provider of medical education, HealthEd, leaked documents and emails from a range of sources show drug company sponsors having input into the selection of some speakers at seminars held in recent years, despite the fact that these have been aggressively sold to general practitioners in brochures claiming that "all content is independent of industry influence."

\section{Doctors in the dark about sponsorship?}

In an email to the drug giant Sanofi-Aventis, HealthEd asks, "Could you please suggest a couple of speakers for our scientific committee's approval?" The drug company emails back: "Please find attached our suggested speakers." One of the speakers suggested by the drug company sponsor is subsequently accepted and delivers a presentation at a HealthEd seminar. Doctors attending that seminar, held at a university, were not verbally informed of the sponsor's role in suggesting speakers.

Another set of leaked emails features communications between the same educational provider and CSL, the company that markets the analgesic tramadol (Tramal) in Australia. While negotiating sponsorship arrangements with the provider, for a planned session on headache, a CSL representative writes that the company would like HealthEd to "determine the speaker's opinion re: Tramal as I would like to ensure he positions it appropriately." HealthEd replies that it "will reconfirm opinion of headache speaker re: Tramal to ensure balanced presentation."

In another email the drug company Organon, now part of Schering-Plough, writes that "we would like to put forward the following two doctors for consideration" as speakers for a seminar on women's health. The educational provider replies, "We will do our best to accommodate your request." The drug company's suggested speakers are ultimately accepted, provoking this grateful response to the educational provider: "I would like to again sincerely thank you for the political help ... in respect of orchestrating the favourable consideration of the proposed topic and speaker."

When asked about its sponsorship arrangements with HealthEd, Schering-Plough's managing director in Australia, Shaju Backer, said that "as part of the sponsorship, [drug] companies are allowed to suggest speakers and topics," which, he added, then undergo a peer review process to see which are suitable. Schering-Plough also made public an extract from an email sent to it by HealthEd, which stated that top level "platinum" sponsors were routinely offered the chance to "work with us to determine a speaker and topic for the programme," subject to conditions that the speaker be authoritative and scientifically balanced and that the content be evidence based. The drug company said it sponsored such meetings to help ensure that drugs are used appropriately in Australia. It stressed that no guarantee is given that the topics or speakers nominated by sponsors will be chosen and that this is not a condition of sponsorship.

\section{Industry suggestions are "filtered"} In an extended interview about sponsorship, HealthEd convenor Ramesh Manocha repeatedly and strenuously defended the content of his seminars as totally independent. He said that suggestions from the industry for speakers were "filtered" through his company's working groups or scientific committees, which commonly include two or three doctors, including himself, and which make decisions entirely independently of industry sponsors. "We filter the suggestions that come from the industry," he said.

In relation to the material in the leaked emails Dr Manocha said they dated back to 2006 and that in all cases decisions about content were made by HealthEd and its working groups, not the industry sponsors. He did, however, concede that measures were not at that time tight enough in relation to the demands of sponsors. "We have accordingly tightened up and established guidelines to prevent them from making these kinds of demands from us." Moreover, he said it was "standard industry practice for sponsors to be involved" in the running of independent educational seminars.

Reacting to specific emails, Dr Manocha said that the speaker suggested by Sanofi-Aventis had been cross checked with independent sources before being accepted and that in the case of the CSL request he admitted talking to the prospective speaker about his presentation but brought no pressure to bear on him. In the case of Organon Dr Manocha agreed that he had asked his scientific committee to accept the speaker suggested by the drug company because he "felt that speaker was a person who was capable of presenting on the topic without being influenced."

Another document that shines light on the relationships between sponsors and educational providers is a 2008 HealthEd brochure that the educational provider had used to seek sponsorship from drug companies. That brochure states that "at each seminar as a platinum sponsor your company can ... work with us to determine a topic that is on message for your product area." Platinum sponsors typically pay the educational provider around \$A10 000 (£4700; $€ 6200 ; \$ 9100)$ to be a sponsor at a one day seminar and receive many entitlements, including stalls in the exhibit area and free passes for their favourite general practitioners.

When asked about the 2008 sponsorship brochure (which the BMJ obtained from a drug company sponsor this month) Ramesh Manocha said that the brochure was no longer used and 


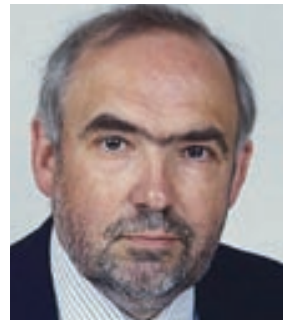

\section{"Who would you suggest we invite to talk about this subject?" \\ Richard Tiner, medical director of the \\ Association of the British Pharmaceutical Industry}

that the wording should have been changed. He did, however, say that for up to $25 \%$ of the sessions at his most recent seminars-specifically the sessions relating to new products-he had sought a list of suggestions from the sponsoring drug company for potential speakers.

\section{Sponsors suggesting speakers is "not unusual"?}

The drug industry's representative body Medicines Australia has confirmed that the practice of inviting input from sponsors into the selection of speakers is by no means uncommon. Its chief executive, Ian Chalmers, said, "It's not unusual in a sponsored professional event for pharmaceutical companies to be offered the opportunity of suggesting speakers."

In an interview with the $B M$ J last week the medical director of the Association of the British Pharmaceutical Industry, Richard Tiner, confirmed that the practice of sponsors suggesting speakers for accredited events also occurred in the UK, where, he said, drug companies fund roughly half of all postgraduate education of general practitioners.

DrTiner said that the organisers of educational meetings might ask their drug company sponsors, "Who would you suggest we invite to talk about this topic?" Drug company sponsorship would then provide funding to bring speakers from outside the local area, so by accepting the sponsors' suggestions for speakers the educational providers "would often get access to speakers they were not able to invite themselves," he said.

The view from the drug industry is that allowing sponsors to suggest speakers does not compromise the independence of medical education, as the educational providers have ultimate control over who speaks. However, research for the investigation in Australia reveals several examples where sponsors' suggestions were embraced by the company providing supposedly independent education. Doctors attending those seminars were not told of this invisible sponsor influence, although during the period when the research was being conducted for this investigation HealthEd made changes to its website, saying that in some cases sponsors are offered a chance to suggest speakers, subject to a list of conditions. ${ }^{1}$

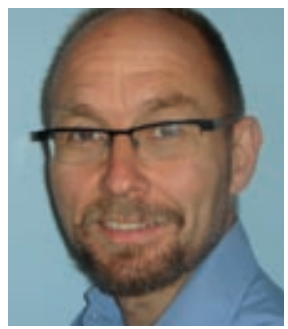

These sponsored
events are
"marketing
masquerading as
education"
Des Spence of
pressure group
No Free Lunch

Disclosure or disentanglement?

Industry representatives in Australia and the UK strongly argue that, in the interests of transparency, doctors attending educational sessions should be fully and explicitly informed if sponsors have suggested speakers for educational sessions. Dr Tiner told the BMJ that his personal view was that he would "have absolutely no problem making it clear, if a sponsor has had input into suggesting speakers-I would have no problem with that whatsoever."

Such a degree of disclosure could radically change perceptions of the content of accredited education, which many doctors believe to be independent of sponsor influence. While welcoming the call for more transparency, Des Spence, of the pressure group No Free Lunch, says that in practice this sort of disclosure would not happen. DrSpence says that in his view these sponsored events are "marketing masquerading as education" and that "it isn't appropriate that industry should be sponsoring education."

The evidence, such as it is, tentatively indicates that the prescribing habits of doctors may be affected by attending sponsored educational events, albeit only in the short term. A survey of doctors who attended courses funded by single drug company sponsors found that after the course "overall the sponsoring drug company's products were favored." ${ }^{2}$ A review of the evidence on interactions between doctors and drug companies, published in 2000 , found that drug company sponsored educational events "preferentially highlighted the sponsor's drug(s) compared with other ... programs."3 An earlier review of the evidence published in 1993 suggested that "company-sponsored... courses may have a commercial bias even if conducted under guidelines designed to ensure the independence of the event." ${ }^{4}$ Although all these findings may have limited applicability to contemporary circumstances, they suggest that sponsorship of educational events may well result in an increase in sales of the sponsor's products.

Harvard professor David Blumenthal, an internationally recognised authority on relationships between doctors and drug companies, says that the industry is certainly looking for a return on its investment in medical education. "Why would for-profit companies, in this country at least (the United States), pour more

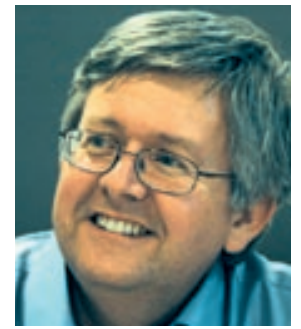

Medical education
should be
funded by the
taxpayer through
competitive
grants
Peter Mansfield of
HealthySkepticism

than a billion dollars a year into continuing medical education without the expectation of gaining anything from it?" he asks.

The obvious problem with allowing sponsors to suggest speakers is that they will tend to select speakers who will at best, from the company's viewpoint, favour their drug or, at least, not contradict the sponsor's marketing messages. The problem is not that individual speakers will change their presentations according to sponsor's wishes; it is that doctors attending these sessions may not be getting the full range of views, in an educational setting supposedly free of industry influence.

In a 2006 paper Professor Blumenthal and colleagues called on US academic medical centres to end the direct drug company sponsorship of continuing medical education events. They suggested the creation of a blind trust to fund education at an institution level..$^{5}$ Others, such as Peter Mansfield from HealthySkepticism, a group critical of pharmaceutical marketing, have called for medical education to be funded by the taxpayer through competitive grants.

Oversight of these educational events is currently a self-regulatory affair, and institutions seem uninterested in guaranteeing independence. Perhaps the recent revelations from Australia-and confirmation from the industry itself that it is "not unusual" for sponsors to suggest speakers-will sharpen the lines of debate about how to achieve more independent education or at least greater transparency.

RM is conjoint lecturer at the Faculty of Health, University of Newcastle, NSW, Australia, and visiting editor, BMJRay.Moynhihan@newcastle.edu.au RM thanks Wendy Carlisle and Miranda Burne for research assistance.

Competing interests: None declared.

CSL and Sanofi-Aventis declined to comment.

1 HealthEd. HealthEd's educational content. www. healthed.com.au/epages/dynamicwebcsoln. storefront/?ObjectPath=/Shops/HealthED/ Categories/about (accessed 15 February 2008).

2 Bowman MA, Pearle DL. Changes in drug prescribing patterns related to commercial company funding of continuing medical education. Journal of Continuing Education in the Health Professions 1988;8:13-20.

3 Wazana A. Physicians and the pharmaceutical industry: is a gift ever just a gift? JAMA 2000;283:373-80.

4 Lexchin J. Interactions between physicians and the pharmaceutical industry: what does the literature say? CMAI 1993;149:1401-7.

5 Brennan TA, Rothman DJ, Blank L, Blumenthal D, Chimonas SC, Cohen JJ, et al. Health industry practices that create conflicts of interest: a policy proposal for academic medical centers. JAMA 2006;295:429-33. 